\title{
Organic agriculture: The science and practices under a changing climate
}

\author{
Abdullah A. Jaradat \\ USDA-ARS \& Department of Agronomy and Plant Genetics, University of Minnesota, MN, USA. E-mail: abdullah.jaradat@ars.usda.gov
}

Organic agriculture may be defined in different ways by different groups (i.e., farmers, agronomists, environmentalists, climate change scientists, and others); however, the large number of designations encountered in the scientific and popular literature for organic agriculture, may represent different production "ideologies." Organic agriculture may encompass any food production system which minimizes the flow of inputs and outputs, sequesters nonrenewable resources, while maintaining, if not increasing, the internal flows of energy, mass and nutrients within the natural boundaries of that system. At a different level of assessment, organic agriculture was considered as a combination of regulations that will ensure efficient use of natural resources and external inputs, and as such, is no different from integrated farm management. Furthermore, in a developing country context, organic agriculture embodies a broad set of practices that highlight farming based on ecosystem management, integrated crop-livestock systems, diversity of farm products, and reliance on natural integrated pest and disease management. Historically, most farms in developing countries are small subsistence crop-livestock family farms, and as such, are considered as organic due to lack or inaccessibility of external synthetic inputs.

Notwithstanding an exact definition, and whether organic agriculture is an ideology, a holistic, but complex natural resources management and food production system, the answer to sustainability, or an answer to the climate change equation, organic agriculture is more than "avoiding chemical inputs and plugging in some organic practices." As an ideology, not all strategies adopted by organic farmers can be applied at a global level and without local modifications; due to this lack of consistency, it may magnify agricultural and environmental problems. However, many in the organic movement consider that organic agriculture, besides its strong social and political agenda, is more than the sum of its parts; they contend that the reductionist view broadly used in the natural sciences does not see the big picture embodied by organic agriculture as a "systems approach which integrates a wide range of practices in an ideal and synergistic fashion.

Climate change refers to complex interactions of bio-geophysical systems within the earth environment with diverse human activities, involving, but not limited to land-use, climate, water, and nutrient changes. Obviously, the climate is changing and, predictably, it will continue to have substantial positive or negative effects on natural resources and agriculture, including water, soil, biodiversity, pests, and pathogens. Climate changes, as demonstrated by global warming, extreme weather events including precipitation, heat waves, greenhouse gas emissions, and their interactions with other environmental stressors, are already affecting the sustainability of agro-ecosystems (both conventional and organic), and disrupting food production. Therefore, on-going and future climate change could aggravate the food insecurity problem to millions, especially in developing countries where multitude forms of organic agriculture with high dependence on limited resources and low-input are being practiced. Under such agro-ecosystems, which are predominantly arid or semi-arid, many crop and livestock species are near their physiological limits for tolerating abiotic stresses such as high temperature and drought. It is predicted that even small changes in abiotic stress levels may have substantial impact on peoples' livelihoods through impacts on the fragile organic and other agroecosystems' sustainability and their ecosystem services. Organic agriculture as a product of the organic movement concerned with healthy soils, food, and people, has been embraced by the mainstream and shows great commercial, social, and environmental promise. If we consider organic agriculture as a system of food production that seeks to minimize the flow of inputs and optimize outputs; sequesters non-renewable resources across the boundaries of the production area while maintaining or increasing the internal flow of mass, nutrients and energy within the system boundaries; then it deserves a new assessment in view of recent climate change, scientific discoveries, trends in production strategies, and labeling and consumption of organic food and feed.

Given its multiple origins around the world, organic agriculture encompasses heterogeneous management methods and practices; it is inextricably linked to climate and will impact and will be impacted by climate change. Unlike conventional agriculture, organic agriculture has little to invest in expensive adaptation strategies; this may increase its vulnerability to climate change. This complex nature of organic agriculture and how it will respond to climate change is a grand challenge which calls for comprehensive analysis, assessment, evaluation, and critique of 
its structural and temporal diversity at several levels, including the germplasm diversity; biodiversity; crops and crop rotations; soils and their biological and nutrient cycling components; management; sustainability; and environmental relationships. The overriding question in this analysis is how and how well organic farmers can, quantitatively and qualitatively, mitigate and adapt the whole system to climate change, while sustainably producing high-value food and other ecosystem services. A challenging research and development endeavor is how productivity and efficiency of organic agriculture can be increased without increasing the risk of environmental pollution.

The International Federation of Organic Agriculture Movement described organic agriculture on the basis of agro-ecological approaches, as being reliant on ecological processes, biodiversity, and cycles adapted to local conditions. As such, organic agriculture may have the potential to substantially contribute to sustainable food production at local, regional, and global scales. Sustainable intensification of organic agriculture may lead to intensifying the beneficial effects of ecosystem services or functions, thus leading to eco-functional intensification. Although it is considered as one of the best developed multi-functional production systems developed by farmers, organic agriculture inherently, and understandably has lower productive capacity than high-input conventional agriculture. Therefore, and in order to circumvent this apparent limitation, organic farmers and practitioners striving to sustainably intensify eco-functionality of organic agriculture need to improve nutrient cycling, enhance crop and livestock diversity, and improve soil health.

Global climate change, especially extreme events of precipitation, temperature, drought, and floods, will impact organic agriculture quantitatively and qualitatively. The adaptive capacity of organic farmers, their farms, and production strategies will become increasingly more relevant to cope with such events in particular, and with climate change, in general. Robust and resilient organic production systems are expected to become more competitive with conventional counterparts as the unpredictability in weather events increases. Indigenous and local knowledge, as an integral component of organic production "know-how" toolbox will become more critical in developing "permanent" adaptation strategies to climate change. Organic farmers can develop a "reservoir of adaptations" on the basis of indigenous knowledge involving management practices such as, but not limited to, farm spatial and temporal organization, design of complex crop rotations to properly cycle nutrients and avoid allelopathy, integration and manipulation of natural and seminatural habitats on or near the farm, selection, pre-breeding and use of adapted crop cultivars and livestock breeds, on-farm composting and fertilizer production, and the use of natural biopesticides in an integrated pest management strategy. Enhanced soil fertility and high organic matter under organic management will help to maintain organic crop productivity under extreme events of drought, temperature, and precipitation; soils will be able to store more rain or irrigation water due to improved water infiltration.

Ecological organic agriculture gained prominence lately due to its promise of increased income, enhanced food security, and social inclusion, and reduced exposure to chemicals and toxins. Integration of ecological and organic principles may provide a solution to food security under climate change in large parts of the developing world, especially in Africa. Research and development efforts on organic agriculture are objectively assessing and quantifying the benefits and impacts of organic agriculture at local and regional scales in developing countries. However, the credibility of this research, and organic agriculture itself, are challenged by regional adaptation, and redesign of organic farming systems suitable for local agronomic, social, and environmental conditions; policies, distribution channels and access to markets. On the other hand, research and development efforts in European organic agriculture enjoy the joint support of industry and civil society; this support is reflected on the already identified huge potential of European organic agriculture to mitigate problems of food security, socioeconomic challenges, and climate change. Organic agriculture in the United States and Canada provide examples of some of the most advanced in the world; however, research and development on organic agriculture face some problems of limited, but growing, capacity and uncertainty in long-term funding.

In Asia, India is the country with the largest number of organic agriculture producers (about 600,000) working on a relatively small land area ( 0.5 million ha); while China is the leading country in land area (1.9 million ha) under organic agriculture. However, improved production practices are needed to realize full potential of organic agriculture in these countries and the rest of South and Southeast Asia. Research and development in this part of the world is supported mainly by international donors and regional foundations, and is focused on organic development, poverty mitigation, capacity building, technology development, certification, and to promote organic education. The Middle East and North Africa region is lagging behind other parts of Asia and Africa in developing organic research and development initiatives.

This special issue of The Emirates Journal of Food and Agriculture furnished an opportunity for advocates, researchers, educators, socio-economists and practitioners of organic agriculture to contribute their experiences and points of view on organic agriculture in an era of climate change. It is expected that this dialogue will continue in the future on the pages of this journal and in social media as well. 